\title{
Degradations of Phenol, Benzoic Acid and Their Derivatives by Microbial Populations in Sea Water
}

\author{
TAKAMITSU YoSHIOKA \\ Maritime Safety Academy, 5-1, Wakaba-cho, Kure, Hiroshima 737, Japan
}

(Received June 27, 1997-Accepted September 18, 1997)

\begin{abstract}
In the course of the studying the microbial degradation of organic compounds in the sea, the degradations of phenol, benzoic acid, $o$-hydroxybenzoic acid, $m$-hydroxybenzoic acid, $p$-hydroxybenzoic acid, $o$-cresol, $m$-cresol and $p$-cresol in sea water were examined. Degradation mixtures were prepared from sea water, collected in Kure Bay, by addition of each substrate, respectively. Then the mixtures were incubated in the dark at $20^{\circ} \mathrm{C}$. Decrease of the substrate was determined on the basis of a quantitative analysis by use of high performance liquid chromatography (HPLC). Judging from the incubation conditions and observations of the degradation mixtures incubated, it was assumed that the microbial degradations of substrates were produced by the bacterial population in sea water. The bacterial population in the mixtures more actively degraded hydroxybenzoic acids and benzoic acid than phenol. To degrade phenol, the bacterial population required an acclimation period of one or two days. However, no or little acclimation was necessary for the degradation of hydroxybenzoic acids and benzoic acid. Cresols were more nondegradable than the other substrates. One or two days acclimation was required for bacterial degradation of cresols, and a considerable proportion of the cresols had not been degraded after 17 days incubation. The degradation curves of cresols showed remarkable differences. It was revealed that degradation of the cresols was influenced by the position of the functional group. On the other hand, no marked difference, arising from their molecular structures, was recognized in the degradation curves of hydroxybenzoic acids.
\end{abstract}

Key words: Microbial degradation, Marine bacteria, Phenol, Benzoic acid, Cresol

\section{Introduction}

In recent years, environmental pollution by wastes of artificial organic compounds has become a social problem. In particular, an accident during marine transportation of chemicals can cause serious pollution of the sea, because it is difficult to recover organic compounds flowing out from a tanker: a recent accident in the Japan Inland Sea inflicted extensive damage on the surrounding areas. In some cases, there is no choice but to wait for nature to clean up the polluted water. In the sea, there are two natural processes by which organic compounds are broken down. One is photolysis attributed to irradiation with sunlight, the other is biodegradation attributed to digestion by natural microbial populations. Most discharged organic chemicals are decomposed to methane, carbon dioxide, and water by microbial populations. However, the chemical structures of organic compounds may affect the mechanism of this degradation. Further, the speed of the microbial degradation may be influenced by environmental factors in the sea, such as water temperature, salinity, nutrient salts, microbial populations, etc. Therefore, it is difficult to presume the fate of organic chemicals discharged in the sea.

Numerous studies on the microbial degradation of 
organic chemicals have been conducted, including a fair number on the degradation of aromatic compounds ${ }^{10,22}$. Furthermore, degradation mechanisms of some organic compounds, included several aromatic compounds, have been proposed or established ${ }^{10,15)}$. However, most studies dealt with degradation in activated sludges ${ }^{6,24)}$ and soils ${ }^{1,8)}$ or degradation by microorganisms isolated from sludges ${ }^{13,14,25)}$ or soils ${ }^{2,7,9)}$. There have been some reports about the degradation of hydrocarbons by microbial populations in sea water ${ }^{3,4)}$ or by bacteria isolated from the sea ${ }^{17,18)}$. In addition, a few studies about the degradation of phenol by bacteria isolated from marine sediment ${ }^{5)}$ and about isolation of bacteria with homologous sequences in DNA for aromatic hydrocarbon degradation $^{23,26)}$ have been published. However, there have been no reports about aerobic microbial degradation of organic compounds on the surface of the sea.

Different pathways, resulting from differences in the biochemical properties of microorganisms used for degradation experiments, have been proposed for the microbial degradation of phenol and aromatic compounds ${ }^{12,16,19)}$. The properties of microorganisms are significantly influenced by environmental factors. Considering the environment peculiar to the sea, there is a little chance of detecting original degradation pathways of organic compounds, especially aromatic compounds, for marine microorganisms.

In the course of studying biodegradation of organic compounds in the sea, the microbial degradations of phenol, benzoic acid and their derivatives were investigated in sea water.

\section{Materials and Methods}

\section{Sea water sampling}

The samples of sea water for the viable counting of bacteria and for the degradation of substrates were collected with a water sampler (Heyroht type) from the surface layer, $50 \mathrm{~cm}$ in depth, at a point in Kure Bay in front of the Maritime Safety Academy. The glass vessel of the water sampler was sterilized with hot air before use.

\section{Viable count of bacteria in sea water}

The sea water sample was diluted 100 times with sea water sterilized by use of an autoclave, and three 0.2 $\mathrm{ml}$ portions of the diluted samples were individually spread on the surface of three ZoBell's 2216E medium plates ${ }^{20)}$. The plates were incubated in the dark at $20^{\circ} \mathrm{C}$ for 7 days. After the incubation, the colonies on the surface of the plates were counted (triplicate).

\section{Substrates}

Phenol, benzoic acid, $o$-hydroxybenzoic acid, $m$-hydroxybenzoic acid, $p$-hydroxybenzoic acid, $o$-cresol, $m$-cresol and $p$-cresol were used as substrates for microbial degradation. All chemicals were of reagent grade and obtained from Katayama Chemical Co., Ltd.

\section{Degradation mixtures}

Degradation mixtures were prepared from sea water by addition of each substrate as follows. The groups of substrates used in the degradation experiments are described in Table 1. In order to compare the facilities in the degradations of substrates, it was necessary that the conditions for microbial degradation, especially the microbial population in the degradation mixture, be exactly the same. Therefore, sea water of the same batch was used for preparations of the degradation mixtures in experiment group No. (1), No. (2), No. (3) and No. (4), respectively. The dates of collection of sea water for the degradation of substrates are shown in Table 1. The degradation in group No. (4) served as a comparison for the degradation of substrates in group No. (1), No. (2) and No. (3).

Each substrate was individually added to sea water at a concentration of $30 \mathrm{mg} / \mathrm{l}$, and $200 \mathrm{ml}$ of the prepared degradation mixture was poured into a $300-\mathrm{ml}$ Erlenmeyer flask with a SILICO ${ }^{\circledR}$ stopper. The flasks were sterilized with hot air before use. Then, the degradation mixtures in flasks were incubated without addition of nutrient salts in the dark at $20^{\circ} \mathrm{C}$. This temp is the average temp of sea water, and the flasks were not illuminated in order to inhibit multiplication of microorganisms that require energy of light. 
Table 1. Groups of the substrates in the degradation experiments

\begin{tabular}{|c|c|c|}
\hline Group No. & Substrates & Dates \\
\hline (1) & $\begin{array}{l}\text { 1. phenol } \\
\text { 2. benzoic acid } \\
\text { 3. control (phenol) }\end{array}$ & July 1, 1996 \\
\hline (2) & $\begin{array}{l}\text { 1. o-hydroxybenzoic acid } \\
\text { 2. } m \text {-hydroxybenzoic acid } \\
\text { 3. } p \text {-hydroxybenzoic acid }\end{array}$ & July 17, 1996 \\
\hline (3) & $\begin{array}{l}\text { 1. } o \text {-cresol } \\
\text { 2. } m \text {-cresol } \\
\text { 3. } p \text {-cresol }\end{array}$ & July 17, 1996 \\
\hline (4) & $\begin{array}{l}\text { 1. phenol } \\
\text { 2. benzoic acid } \\
\text { 3. o-hydroxybenzoic acid } \\
\text { 4. o-cresol }\end{array}$ & August 2, 1996 \\
\hline
\end{tabular}

Table 2. Analytical conditions of HPLC

\begin{tabular}{ll}
\hline Column & ZORBAX-ODS \\
Column oven temp & $37^{\circ} \mathrm{C}$ \\
Elution solvent & $0.1 \% \mathrm{H}_{3} \mathrm{PO}_{4} /$ Acetonitrile \\
Gradient rate & $30-50 \%$ (Acetonitrile) $/ 25 \mathrm{~min}$ \\
Elution rate & $0.8 \mathrm{ml} / \mathrm{min}$ \\
Detector & Photodiode array UV-VIS detector \\
\hline
\end{tabular}

\section{Measurement of substrate concentration}

The concentrations of substrates were determined by use of HPLC under the analytical conditions described in Table 2. At a wave length of an absorption maximum in a UV spectrum of a substrate, absorbance was measured for making out a calibration curve. The calibration curves were confirmed by the least-squares method, and employed for the evaluation of substrate concentrations in degradation mixtures.

\section{Results and Discussion}

Seasonal changes in the number of bacteria in sea water collected in Kure Bay are described in Fig. 1. The changes in temp, $\mathrm{pH}$ and concentration of chloride ions of sea water are shown in Fig. 2. In June, the

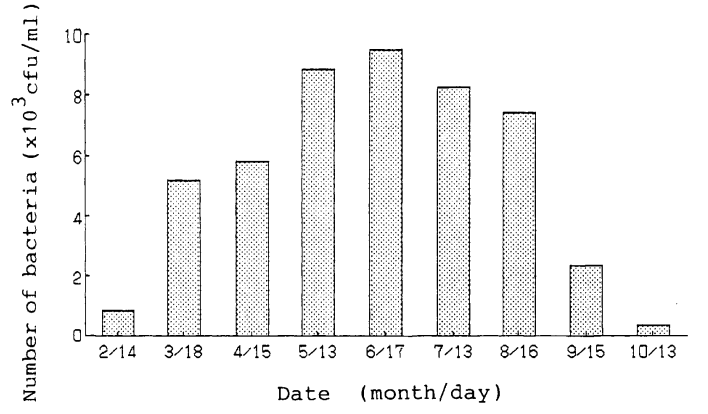

Fig. 1. Seasonal changes in the number of bacteria in sea water in Kure Bay.

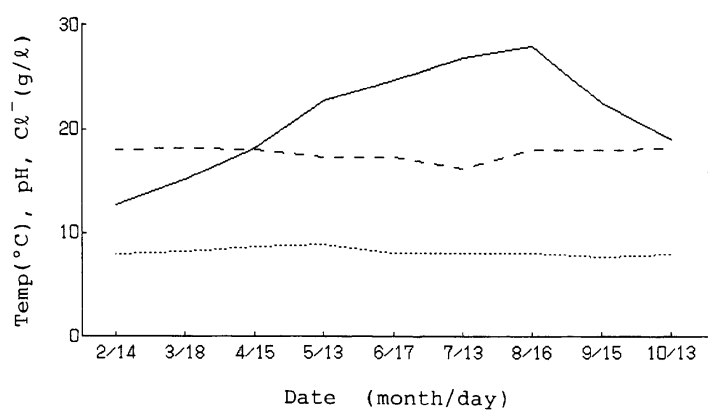

Fig. 2. Seasonal changes in temp (-), pH ( …) and concentration of chloride ion $\left(-{ }^{--}\right)$of sea water.

number of bacteria in sea water increased to a maximum. From May to August, the number of bacteria was maintained at over $8.0 \times 10^{3} \mathrm{cfu} / \mathrm{ml}$. It was presumed that the amount of carbon and nutrient salts in the sea was increased by the action of primary food producers with the rise of temp, and that this, along with high water temp (above $20^{\circ} \mathrm{C}$ ), allowed the marine bacteria to multiply successively and maintain high density. Based on this speculation, we believe the season from May to August to be the most suitable for collecting sea water for use in degradation experiments.

The degradation mixture became slightly muddy with the passing of incubation time. However, the mixture showed no color characteristic of photosynthetic microorganisms, nor any floating particles of mold. Furthermore, it is known that bacteria, such as Pseudomonas sp., show resistance to aromatic compounds and degrade them. For the reasons mentioned 
above, the phenomena that occurred in the degradation mixture were considered to have been caused by the multiplication of the bacterial population in sea water.

As shown in Fig. 3 (Degradation Experiment Group No. (1) in Table 1), the concentration of phenol and benzoic acid decreased markedly in comparison with the control. In the control experiment, phenol was the substrate for degradation, and the degradation mixture was sterilized in an autoclave to sacrifice the microbial population in the mixture. Therefore, this decrease of substrate resulted from the degradation of substrates by the bacterial population in sea water. For the degradation of phenol, the bacterial population required an acclimation period of one or two days. After 17 days incubation, the concentration of the residual substrate was almost $8 \mathrm{mg} / \mathrm{l}$ in this closed system. However, no or little acclimation was required for the degradation of benzoic acid, and no benzoic acid remained after 15 days incubation. It was demonstrated that the bacterial population in the degradation mixtures degraded benzoic acid more actively than phenol. The brief acclimation suggested that benzoic acid was easily introduced in the degradation pathways of the bacterial population in comparison with phenol. However, the degradation mechanisms of phenol and benzoic acid were not revealed by these experiments, because the intermediary metabolites were not identified by the HPLC analysis.

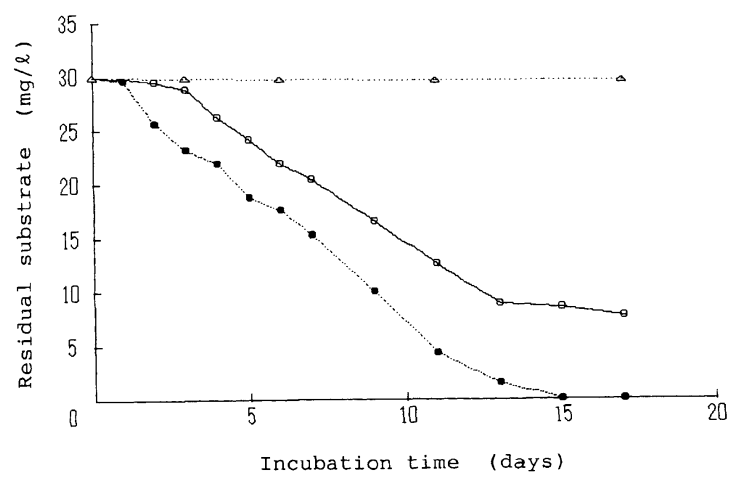

Fig. 3. Bacterial degradations of phenol $(O)$ and benzoic acid (•) in sea water and the control experiment $(\triangle)$.
The results of the degradation of hydroxybenzoic acids (Group No. (2) in Table 1) are shown in Fig. 4. The degradations of $o$-, $m$ - and $p$-hydroxybenzoic acid were initiated without acclimation. After 11 days incubation, these hydroxybenzoic acids were degraded in a short time in comparison with phenol and benzoic acid, suggesting that hydroxybenzoic acids were easily introduced in the degradation pathways of the bacterial population. The slope in the degradation curve of $m$-hydroxybenzoic acid was a little gentler than that in the curves of the other isomers. However, there was no remarkable distinction in the curves. This suggested that the degradation of hydroxybenzoic acids was little influenced by the difference in the molecular structures of substrates.

The degradation curves of $o$-, $m$ - and $p$-cresol are shown in Fig. 5 (Degradation Experiment Group No. (3) in Table 1). The slopes in the curves of cresols were gentle in comparison with the other substrates. The slope of $o$-cresol was a little steeper than those of the other isomers, and the concentration of $o$-cresol decreased suddenly after three days acclimation. The concentrations of $m$ - and $p$-cresol gradually decreased after acclimation for a day or two. After 17 days incubation, a considerable proportion of cresols had not been degraded. In the case of the degradation of $m$ cresol, half the substrate remained after 17 days incubation. These results suggested that it was difficult for cresols to be introduced in the degradation path-

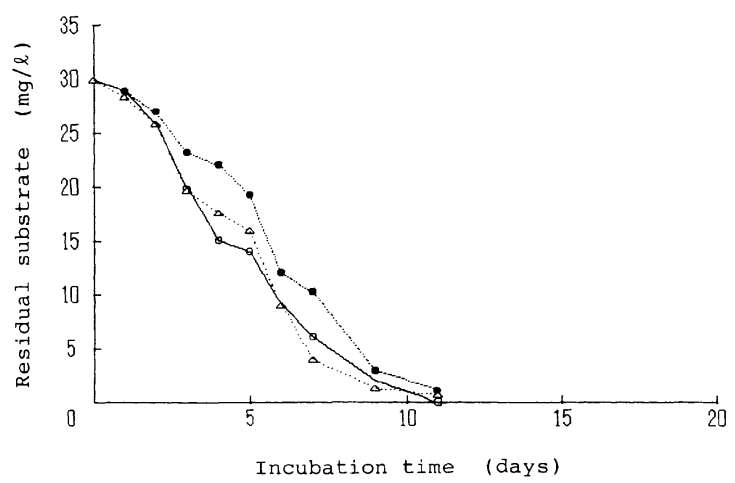

Fig. 4. Bacterial degradations of $o$-hydroxybenzoic acid $(O)$, $m$-hydroxybenzoic acid $(\bullet)$ and $p$-hydroxybenzoic acid $(\triangle)$ in sea water. 


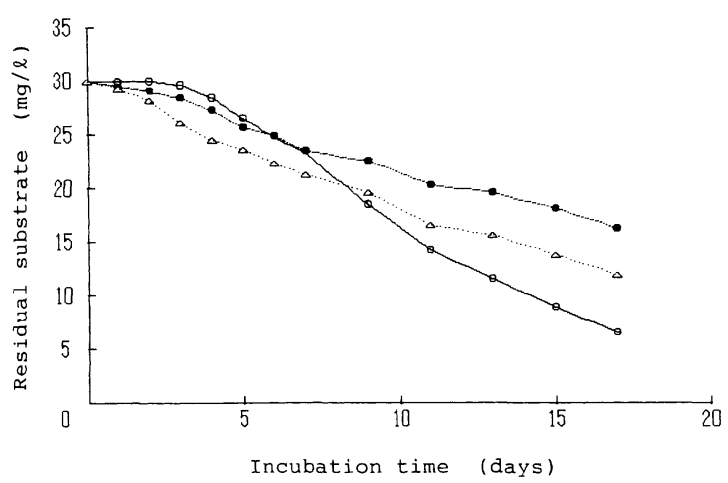

Fig. 5. Bacterial degradations of $o$-cresol $(\bigcirc), m$-cresol $(\bullet)$ and $p$-cresol $(\triangle)$ in sea water.

ways of the bacterial population in comparison with the other substrates, and implied that $m$-cresol was the most nondegradable of the substrates used in these experiments. The values of the concentration of residual substrates varied widely $(17,13$ and $7 \mathrm{mg} / \mathrm{l})$ after 17 days incubation. The remarkable distinction in the degradation curves of cresols was suggestive of the difference in the damage to the bacteria by cresols and/or of the difference in the degradation mechanism of cresols.

The degradation experiments (Group No. (4) in Table 1) were necessary to confirm the facilities in the degradation of phenol, benzoic acid, hydroxybenzoic acids and cresols in the same degradation conditions. In this degradation experiment, the $o$-isomers of hydroxybenzoic acids and cresols were chosen for their ease of bacterial degradation in comparison with the other isomers, respectively. The results of the degradation of phenol, benzoic acid, $o$-hydroxybenzoic acid and $o$-cresol are shown in Fig. 6 . In the case of the degradation of $o$-hydroxybenzoic acid and benzoic acid, no substrate remained after 15 and 17 days incubation, respectively. On the other hand, the concentrations of the residual phenol and $o$-cresol were 5 $\mathrm{mg} / \mathrm{l}$ and $12 \mathrm{mg} / \mathrm{l}$, respectively, after 17 days incubation. The degradation of each substrate in the experiment (Group No. (4)) was a little slow compared with the degradation of the same substrate in the other experiments (Group No. (1), (2) and (3)), respectively. It was considered that this delay of degradation

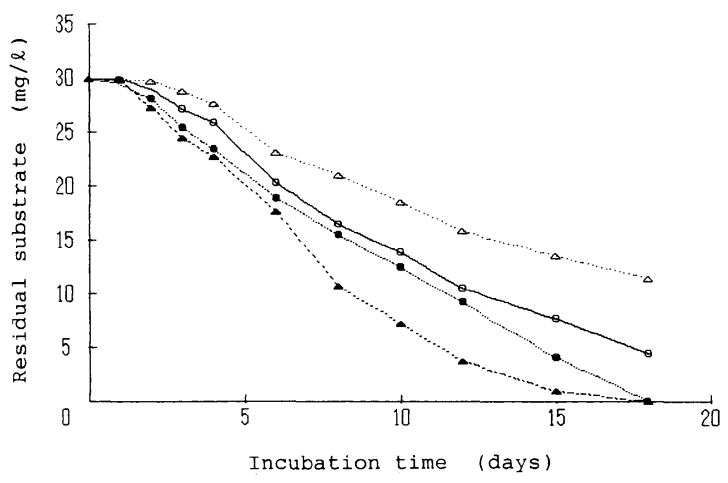

Fig. 6. Bacterial degradations of phenol $(O)$, benzoic acid $(\bullet), o$-hydroxybenzoic acid $(\boldsymbol{\Delta})$ and $o$-cresol $(\triangle)$ in sea water.

(Group No. (4)) was caused by a slight difference in composition between the sea water collected on August 2 in 1996 and the other samples. By these degradation experiments, however, it was ascertained that the order of facility in the degradation of substrates was as expected.

On the basis of the degradation experiments described above, it is possible to estimate the order of facility in the bacterial degradation for the substrates. It can be assumed that the facility in degradation must be closely related to the molecular structure of substrates. Hydroxybenzoic acids and benzoic acid, especially hydroxybenzoic acids, are easily introduced in the degradation pathways of the bacterial population in comparison with phenol. This facility in degradation must be dependent on the molecular structure of benzoic acid. Furthermore, the substitution of a hydroxyl group for an aromatic hydrogen of benzoic acid tends to facilitate the bacterial degradation, regardless of the position of the hydroxyl group. Cresols are more nondegradable than phenol. This nondegradable behavior may arise from damage to the bacteria by cresols and/or from structural problems of cresols affecting the degradation mechanism. The degradation of cresols is remarkably affected by the position of the hydroxyl group. Among the three isomers of cresol, $o$-cresol was degraded most actively by the bacteria. On the other hand, $m$-cresol shows the strongest resistance to bacterial degradation. The results described above imply 
that it may be possible to evaluate the period needed for cleaning up areas such as the Japan Inland Sea that have been polluted with the organic compounds used in this study.

The facility in degradation of these substrates gave a clue to the elucidation of the degradation pathways of bacterial populations for aromatic compounds. In particular, it was noted that the position of the hydroxyl group was closely related to the degradation mechanism of the aromatic ring. In a previous review on the bacterial catabolism of aromatic compounds in anaerobic environments, it was proposed that phenol and benzoic acid are immediately hydrogenated, respectively, prior to cleavage of an aromatic ring ${ }^{12)}$. However, another pathway, in which benzoic acid is the intermediary metabolite, has been presented for the degradation of phenol in acclimated sludges ${ }^{16}$. According to this degradation pathway, phenol is converted into benzoic acid prior to hydrogenation of an aromatic ring and cleavage of an aliphatic ring. Furthermore, the degradation pathways of aromatic compounds, in which there are three key intermediates with two hydroxyl groups, catechol, 3,4-dihydroxybenzoic acid (protocatechuic acid) and 2,5-dihydroxybenzoic acid (gentisic acid), were presented in another review of hydrocarbon fermentation by bacteria ${ }^{15)}$. In these pathways, an aromatic compound is oxidized to one of three intermediates, and the produced intermediate directly degraded to keto acid. Then, both catechol and protocatechuic acid are degraded to $\alpha$ keto acid or $\beta$-ketoadipic acid along two types of cleavage pathways, and gentisic acid is degraded to fumarylpyruvic acid.

The order of facility for the degradation of substrate described in this paper suggests that substrates easily introduced in the degradation pathways are intermediary metabolites. Alternatively, it can be assumed that phenol is converted to benzoic acid and that benzoic acid is oxidized to hydroxybenzoic acid in the degradation pathways of bacterial populations in the sea. However, these assumptions have not be ascertained and the degradation mechanism of aromatic compounds in sea water was not elucidated because the intermediary metabolites in the degradation of substrates were not identified. To clarify in detail the degradation mechanism of the derivatives of phenol and benzoic acid, one must carry out degradation experiments using cultures of bacteria isolated from sea areas or using a crude enzyme system ${ }^{11,21)}$ prepared from marine bacteria.

\section{References}

1) Abe, S. and M. Seno. 1987. Biodegradation of sodium linear alkylbenzenesulfonates evaluated with a soil perfusion method. J. Am. Oil Chem. Soc. 64: 148-152.

2) Adriaens, P., H.P.E. Kohler, D. Kohler-staub and D.D. Focht. 1989. Bacterial dehalogenation of chlorobenzoates and coculture biodegradation of 4,4'dichlorobiphenyl. Appl. Environ. Microbiol. 55: 887-892.

3) Atlas, R.M. and R. Bartha. 1972. Degradation and mineralization of petroleum in sea water. Limitation by nitrogen and phosphorous. Biotechnol. Bioeng. 14: 309-318.

4) Atlas, R.M. and R. Bartha. 1972. Biodegradation of petroleum in sea water at low temperatures. Can. J. Microbiol. 18: 1851-1855.

5) Bak, F. and F. Widdel. 1986. Anaerobic degradation of phenol and phenol derivatives by Desulfobacterium phenolicum sp. nov. Arch. Microbiol. 146: 177-180.

6) Ball, H.A., M. Reinhard and P. McCarty. 1989. Biotransformation of halogenated and nonhalogenated octylphenol polyethoxylate residues under aerobic and anaerobic conditions. Environ. Sci. Technol. 23: 951-961.

7) Bedard, D.L., M.L. Haberl, R.J. May and M.J. Brennan. 1987. Evidence for novel mechanisms of polychlorinated biphenyl metabolism in Alcaligenes eutrophus H850. Appl. Environ. Microbiol. 53: 1103-1112.

8) Bossert, I.D. and R. Bartha. 1986. Structure-biodegradability relationships of polycyclic aromatic hydrocarbons in soil. Bull. Environ. Contam. Toxicol. 37: 490-495.

9) Chandra, T., W. Madhavakrishna and Y. Nayudamma. 1967. Astringency in fruits. I. Microbial degradation of catechin. Can. J. Microbiol. 15: 303-306.

10) Dugan, P.R., in "Biochemical ecology of water pollution”, Plenum Press, New York, 1972.

11) Elsner, A., F. Loffler, K. Miyashita, R. Muller and F. Lingens. 1991. Resolution of 4-chlorobenzoate dehalogenase from Pseudomonas sp. strain CBS3 into three components. Appl. Environ. Microbiol. 57: 324-326.

12) Evans, W.C. 1977. Biochemistry of the bacterial 
catabolism of aromatic compounds in anaerobic environments. Nature, 270: 17-22.

13) Grbic-galic, D. and L.Y. Young. 1985. Methane fermentation of ferulate and benzoate. Anaerobic degradation pathways. Appl. Environ. Microbiol. 50: 292-297.

14) Hashimoto, K. 1970. Oxidation of phenols by yeast. I. A new oxidation product from $p$-cresol by an isolated strain of yeast. J. Gen. Appl. Microbiol. 16: 1-13.

15) Humphrey, A.E. 1967. A critical review of hydrocarbon fermentations and their industrial utilization. Biotechnol. Bioeng. 9: 3-24.

16) Kobayashi, T., T. Hashinaga, E. Mikami and T. Suzuki. 1989. Methanogenic degradation of phenol and benzoate in acclimated sludges. Wat. Sci. Tech. 21: $55-65$.

17) Murakami, A., K. Suzuki, A. Yamane and T. Kusama. 1985. Degradation of crude oils by Pseudomonas sp. in enriched seawater medium. J. Oceanogr. Soc. Jpn. 41: 337-344. in japanese.

18) Murakami, A., T. Matsuda, N. Watanabe and S. Nagasawa. 1976. Degradation of $n$-paraffin mixture by marine microorganisms in enriched seawater medium. J. Oceanogr. Soc. Jpn. 32: 242-248. in japanese.

19) Nakazawa, T. and T. Yokota. 1973. Benzoate metabolism in Pseudomonas putida (arvilla) mt-2. Demonstration of two benzoate pathways. J. Bacteriol. 115: 262-267.
20) Oppenheimer, C.H. and C.E. ZoBell. 1952. The growth and viability of sixty-three species of marine bacteria as influenced by hydrostatic pressure. J. Mar. Res. 11: 10-18.

21) Ribbons, D.W. and P.J. Senior. 1970. 2,3-Dihydroxybenzoate 3,4-oxygenase from Pseudomonas fluorescens. Oxidation of a substrate analog. Arch. Biochem. Biophys. 138: 557-565.

22) Skryabin, G.K. and L.A.M. Golovleva, in "Microorganisms in Organic Chemistry", Nauka, Moscow, 1976.

23) Sotsky, J.B., C.W. Greer and R.M. Atlas. 1994. Frequency of genes in aromatic and aliphatic hydrocarbon biodegradation pathways within bacterial populations from Alaskan sediments. Can. J. Microbiol. 40: 981-985.

24) Tiedje, J.M., S.A. Boyd and B.Z. Fathepure. 1987. 13. Anaerobic degradation of chlorinated aromatic hydrocarbons. Dev. Ind. Microbiol. 27: 117-127.

25) Urushigawa, Y., S. Masunaga and Y. Yonezawa. 1988. Physico-chemical parameters determining the relative biodegradability of para-substituted phenols by bacteria isolated from activated sludge. Wat. Sci. Tech. 20: 459-461.

26) Wang, Y., P.C.K. Lau and D.K. Button. 1996. A marine oligobacterium harboring genes known to be part of aromatic hydrocarbon degradation pathways of soil pseudomonads. Appl. Environ. Microbiol. 62: 2169-2173. 